\title{
Bank Capital and Loan Loss Reserves under Basel II: Implications for Emerging Countries
}

\author{
Giovanni Majnoni, Margaret Miller, and Andrew Powell*
}

\begin{abstract}
This paper proposes an integrated approach to minimum bank capital and loan loss reserves regulation. The paper breaks new ground in two main areas. In the first place it provides an explicit measurement of the credit loss distribution for a sample of emerging countries providing a benchmark for discussing the appropriate calibration of new regulatory capital and loan loss provision requirements for non-G10 countries. Second, on normative grounds, it proposes a simplified version of the "internal rating based" (IRB) approach as a transition tool that, while retaining a risk-based definition of solvency ratios, implies reduced supervisory monitoring costs and could therefore be of interest to emerging countries where supervisory resources are particularly scarce.
\end{abstract}

\section{JEL Classification: G21, G28}

Keywords: Bank regulation, solvency ratios, loan loss reserves, emerging economies.

\section{World Bank Policy Research Working Paper 3437, October 2004}

The Policy Research Working Paper Series disseminates the findings of work in progress to encourage the exchange of ideas about development issues. An objective of the series is to get the findings out quickly, even if the presentations are less than fully polished. The papers carry the names of the authors and should be cited accordingly. The findings, interpretations, and conclusions expressed in this paper are entirely those of the authors. They do not necessarily represent the view of the World Bank, its Executive Directors, or the countries they represent. Policy Research Working Papers are available online at http://econ.worldbank.org.

\footnotetext{
* The authors are from the World Bank (Giovanni Majnoni and Margaret Miller) and from the Universidad Torcuato Di Tella (Andrew Powell). This paper has been completed as part of a project on "Credit Information, Credit Risk Measurement, and Solvency Ratios in Emerging Countries" supported by a grant from the World Bank Research Committee. Andrew Powell gratefully acknowledges the World Bank, where he visited between August and December 2003, for financial support. Email: gmajnoni@worldbank.org, mmiller5@worldbank.org, apowell@utdt.edu. We are grateful to Matias Gutierrez from the Banco Central de la Republica Argentina, Jose Luis Negrin, Javier Marquez, and Alberto Romero from Banco de Mexico, and Ricardo Schectman from Banco Central do Brazil for invaluable help and support in the quantitative analysis. We thank Jerry Caprio and Patrick Honohan for comments on an earlier draft.
} 


\section{Introduction}

The debate regarding the appropriate regulation of bank capital and provisions has come to the fore given the recent discussions regarding the proposed revisions to the Basel Capital Accord, known as Basel II. This proposal, developed by the 13 member countries of the Basel Committee for Banking Supervision (BCBS) is to be finalized this year for implementation in member countries by 2006. An underlying discussion hinges on whether regulatory capital should be related to risk. ${ }^{1}$ We take this as a given and focus on the subsequent issue; if required capital is to be risk-related, how should this be achieved?

Basel II proposes two basic approaches; (i) the use of external credit ratings agencies and a table that maps those ratings into capital requirements (this is known as the standardized approach) and (ii) the use of banks' internal ratings, that banks then map into default probabilities, and a particular formula laid down by the BCBS that determines capital requirements as a function of the default probability and other parameters (this is known as the internal rating based or IRB approach). ${ }^{2}$

This paper focuses on two main issues. First we investigate whether the IRB approach's formula is appropriately calibrated for the context of emerging economies. To do this we must first estimate credit risk. In a set of companion country papers ${ }^{3}$ this is

\footnotetext{
${ }^{1}$ See the many papers on the BIS website on the Accord www.bis.org.

2 See Basel Committee for Banking Supervision (2003).

${ }^{3}$ See Balzarotti et al. (2003) for credit risk measurement in Argentina, Cronenberger et al. (2003) in Brazil, and Marquez et al. (2003) in Mexico. See also Foglia (2003) for a rich series of applications of credit risk measurement to regulation and supervision in G10 countries. All papers can be accessed on the World Bank website: www.econ.worldbank.org/programs/credit_reporting/topic/22476/
} 
done by the use of a credit-scoring model, to estimate default probabilities, and then the use of a credit risk portfolio model ${ }^{4}$ to combine individual instrument default probabilities into the probability distribution of losses for a portfolio. In this paper we take a second and arguably a simpler approach and employ a direct sampling or bootstrapping methodology as proposed in Carey (2002). The great advantage of this technique is that it makes it reasonably easy to produce comparable statistics across banks and across countries. We believe that this is the first paper to present estimates of credit risk across a set of emerging economies using a homogenous methodology. More importantly, we show the difference between the level of expected and unexpected losses for G10 countries and a sample of emerging economies and illustrate how important the proper calibration of bank capital and loan loss reserves is to achieve the desired level of risk coverage.

Second, we propose a Basel II implementation strategy for emerging economies where such calibration skills could play a vital role. Currently, many of the more sophisticated emerging countries may fall between two stools. On the one hand, the penetration of external ratings agencies is typically low and hence the standardized approach would yield little in linking regulatory capital to risk. ${ }^{5}$ This argument may also be made considering the portfolio of some smaller or regional banks in G10 countries. However, in the case of emerging countries the majority of the portfolios of large and systemic banks are un-rated. On the other hand, the set of procedures embedded in the IRB approach may be difficult to implement in emerging economies. For example, the

\footnotetext{
${ }^{4}$ In the case of the paper on Argentina, Creditrisk+, a model developed by Credit Suisse Financial Products of CSFB.

${ }^{5}$ See Ferri, Liu and Majnoni (2001) for discussion on the global pattern of ratings.
} 
IRB approach gives a high degree of autonomy to banks, to employ their own rating methodologies and their own mappings of their ratings to default probabilities, and requires bank supervisors to control the process, without considering that the sophistication and the resources of both banks and especially bank supervisors does not match that of their G10 counterparts. Considering the data on compliance with the Basel Core Principals of Effective Banking Supervision across developing countries, it may be a significant period of time before many countries would be advised to implement IRB. ${ }^{6}$

In lieu of this situation, we suggest a simplification of the IRB approach that builds on the current policies regarding provisioning in some emerging countries and that may be used as a transition arrangement toward IRB. We name this the centralized rating based (CRB) approach. Within this approach banks would rate their clients. However, the rating scale and the way in which the banks' ratings mapped into default probabilities would be determined by the regulator. ${ }^{7}$ The use of a centralized scale would facilitate comparison across banks and would greatly ease monitoring of banks' ratings ${ }^{8}$. Moreover, as the regulator would determine how banks' ratings would feed into capital requirements, those requirements would also be easier to monitor.

\footnotetext{
${ }^{6}$ As reviewed in Powell (2004), the average developing country is only compliant with 7 of 30 Basel Core Principles.

${ }^{7}$ To a large extent the IRB proposals build on what large sophisticated international banks have been doing for some years. In the case of these institutions it would be very restrictive to impose a standard rating scale. In many emerging countries, banks have only very recently begun to develop such internal risk management functions and they are much less developed. Hence while the system is clearly more restrictive than the IRB approach, the starting point is very different.

${ }^{8}$ For banks lending to the same corporate client, bank ratings could be compared directly. Bank ratings for similar types of loans (to companies in the same economic sector, business line or region) could also be compared and outliers investigated. Informally some G10 regulators acknowledge that even where IRB likely to be employed, supervisors will compare banks' internal ratings of important corporate clients (as they do today) and for that purpose will no doubt map ratings into a centralized scale.
} 
We propose this transition measure as an initial means to enhance forwardlooking provisioning rules and monitoring. Thus, if capital is set by Basel II's standardized approach, and the CRB's default probabilities are used to appropriately determine the value at risk (equal to expected plus unexpected loss), then the CRBdetermined forward-looking provisioning requirement would simply be the value at risk minus the standardized approach's capital requirement. As banks' and supervisors' knowledge and skills improve over time, banks may then be authorized to use their own ratings scales and default probability mappings and capital to be determined by the IRB approach itself. Naturally whether this approach or the IRB approach is appropriate will rest in part on whether the formula linking default probabilities to capital requirements is appropriate for the context at hand - the first issue.

The paper proceeds as follows. Section 2 presents the criteria followed in the construction of our measure of the probability distribution of credit losses and derives from it a quantification of the value of bank capital and loan loss reserves. Section 3 will present the results and compare the values of capital associated with predefined insolvency levels with the regulatory capital required under the IRB foundation approach. Section 4 will show how the previous evidence can provide the basis of an integrated regulatory approach to loan loss reserves and capital. Section 5 concludes.

\section{Methodology and Data}

The most commonly used methodologies to estimate the credit loss distributions of a loan portfolio (be it the aggregate portfolio of the banking system or of a bank or of a particular business-line of a bank) are model-based approaches. In general, individual 
instrument default probabilities are estimated using an econometric model and then these and other parameters are introduced into the model to obtain the loss distribution curve for the portfolio. ${ }^{9}$ Simplifying assumptions are employed both at the stage of the estimation of the parameters (estimation risk) and in developing the model (model risk). Often it is even difficult to measure what distortions both types of risks may induce on the on the predictions that these models generate.

For example, commonly used models - such as the KMV option based model, the McKinsey macro simulation model, the (JPMorgan offshoot) Riskmetrics' Creditmetrics model, the Credit Swiss First Boston's Creditrisk+ model - rely on assumptions concerning the number of risk factors, and the estimation of the factor loadings, factors' volatilities, and factors' correlations. Such estimations are subject to greater error in the context of emerging economies, where often information is of a poorer quality and regime changes may be more frequent. Moreover, the estimation of each model relies on a set of quite specific data requirements and assumptions that make cross-country and even cross institution comparisons problematic. ${ }^{10}$

For these reasons, in this paper we take a different approach intended to minimize the impact of such errors on the estimation of the credit losses distribution function and to maximize the degree of comparability across countries. Following Carey (2002) we adopt a bootstrapping technique that essentially enables us to mimic the shape of the loss distribution function of any specific loan portfolio. Notwithstanding the lack of an

\footnotetext{
${ }^{9}$ See Balzarotti, Falkenheim and Powell (2003) for one example.

10 The companion papers on Argentina and Mexico follow similar methodologies to a large extent but are not exactly comparable as data sources are different and specific assumptions inevitably may also differ.
} 
underlying model, bootstrapping techniques can be used to simulate the impact that specific shocks or cyclical impulses have on the frequency distribution of credit losses. The re-sampling approach is very flexible and lends itself to many alternative simulation exercises aimed, for example, at measuring the exposure to credit losses of portfolios composed of loans of different size, maturity and rating granted to a specific industry or geographic region. An example of how the aggregate results for the banking system can be broken down and separately analyzed for banks of different size is presented, with reference to the Mexican case, in the Appendix.

In line with the methodological aim of this paper, we have conducted a reasonably basic bootstrapping exercises aimed at simply replicating the distribution of credit losses prevailing at a specific period of time ${ }^{11}$ and in three countries; namely Argentina, Mexico and Brazil. We view this as a first step and suggest later what follow-up work might be of interest on a wider country sample. ${ }^{12}$

In each of the three countries the Central Bank maintains a Public Credit Registry (PCR) that contains information on a very large number of loans in the financial system. The objectives and design of these databases is the subject of Miller (2003) and in a companion paper we explore further the design issues, given the potential of these databases as tools to analyze credit risk (Majnoni, Miller, Mylenko, and Powell, 2004). The first step of the procedure consists of extracting, from the PCR, a large pool of performing loans to the (non-financial) corporate sector at a particular date. This pool

\footnotetext{
${ }^{11}$ Typically we consider the default experience over a 12-month period.

${ }^{12}$ Simple modifications of the sampling procedures (Carey, 2002) or of the selection of loans extracted from the Credit Registers would enable to select predefined risk profiles and visualize very effectively the different risk embedded in specific forms of risk exposure.
} 
then reflects the overall risks of lending to the corporate sector in each particular country. Second, we define default as the event of more than 90 days past due payments. ${ }^{13}$ Third, we classify loans into two different categories according to whether they have maintained their initial status or have defaulted over the following twelve months. Fourth, we randomly sample from this pool of loans a pre-defined number of loans (in our case 500), intended to mimic the loan portfolio of a medium-sized bank. Given a predefined recovery ratio (assumed here to be equal to $50 \%$ of the face value of a defaulted loan) we compute the value of the losses of the sampled portfolio, expressing this as a fraction of the face value. Fifth, we replicate the last step a large number of times $(20,000$ in our case) to generate a frequency distribution of credit losses that mimics the one faced by banks.

This technique allows us to replicate the real risks faced by banks without specific knowledge or assumptions regarding the factorial structure of risk or the correlation among different risk factors. The lack of an underlying model precludes simulation exercises, based say on the shocks to specific factors, but does not prevent us from quantifying the amount of capital and provisions that are necessary to shelter a bank from the risk of default at any level of probability. This is of course of prime interest to the banking regulator for considering the appropriate design of solvency rules, as discussed more in detail in Section 4.

Charts 1 to 3 illustrate, for the three countries, the frequency distribution of three variables involved in the experiment. Panel a reports the frequency distribution of the size

\footnotetext{
${ }^{13}$ This follows the typical definition of a non-performing loan according to international best practices and to one of the criteria suggested by the Basel Committee.
} 
of individual loans, extracted from the PCRs, and that represent the universe from which our samples of 20,000 loans are drawn; panel b shows the frequency distribution of the dollar value of the 20,000 randomly selected portfolios; and finally, panel c shows the distribution of credit losses of the 20,000 randomly selected portfolios as a fraction of the face value of the respective portfolios.

A visual inspection of the charts shows clear differences among the three samples. The concentration of loan-dimension toward the smallest size category is more evident in Argentina (50 percent of all the loans extracted from the credit register are smaller than US\$100,000) and in Mexico (80 percent of all the loans extracted from the credit register are smaller than US\$100,000).Due to the different sample construction method adopted in Brazil, loans smaller than US\$100,000 appear to be less numerous (37\%), as they only represent the portion of small loans that are part of global exposures larger than US $\$ 300,000$. The different definition of the universe is reflected in the distribution of the sampled portfolios and of their exposure to credit losses. The charts for Mexico and Argentina show considerably more skewed distributions for both portfolios' value and credit losses than the comparable distribution computed for Brazil. As a supplement to the visual information provided by the charts, we have summarized in Table 1 a set of descriptive statistics of the distribution of the 20,000 randomly sampled portfolios.

\section{Empirical Results}

The main results of the samples just described are reported in Table 2, where we have indicated for each country the value of expected losses (EL) and the value of unexpected losses (UL) associated to each percentile level of the (right tail of the) 
simulated distribution of credit losses. Here we refer to the total amount of losses equal to the sum of the expected and unexpected component as the value at risk. The value at risk and its components, the expected and unexpected loss, are critical in defining the volume of bank capital and loan loss reserves necessary to achieve a predefined level of protection for the banking system.

However, before commenting in detail on the simulation results we would like to state an important caveat upfront. Data limitations have not allowed sampling over several years and therefore the simulation results reported in Table 2 should be interpreted as reflecting a photograph or snap-shot of a particular country in a particular year. The results cannot and should not be interpreted as average values representing credit risk exposure over different time horizons, nor over the full economic cycle. While a robust parameterization for capital and loan loss reserves requires data spanning at least a whole cycle the evidence that we present here support the need of a careful calibration effort and for a new regulatory approach to capital and loan loss reserves in emerging economies.

In the case of Argentina, the results reflect the events of 2001. In that year there was a recession that led to a fall of GDP equal to $4.4 \%$ in real terms and a crisis that was growing exponentially in terms of its depth. In December 2001, bank deposits were frozen and there was considerable economic and political uncertainty. Over the same period, Mexico experienced a stagnation of economic activity with GDP growth equal to zero and a reduction of bank credit to GDP to $11.9 \%$, the lowest value of the last decade. Not dissimilar was the situation in Brazil where a slowdown of economic activity brought GDP growth down to only $1.3 \%$ and led to a contraction of bank credit in real terms. To 
summarize, while the results will naturally reflect a period in time, the snap-shot reflects economic stress in all three countries and recession, albeit not the worst of the crisis, in one country (Argentina).

With this qualification, Table 3 presents our results and compares them with those associated to the Basle II requirements and with S\&P historical evidence of default rates. Simulation results provide a measure of the size of expected losses and unexpected losses and of the values that capital and loan loss reserves need to achieve to protect banks from insolvency in $95 \%, 99 \%$ or $99.9 \%$ of negative occurrences - or $95 \%, 99 \%$ and $99.9 \%$ of the distribution. For the three countries considered, expected losses proved to be in an interval between $1 \%$ and $5 \%$ (column 2). Assuming provisions to cover this amount, the amount of capital necessary to provide protection for UL up to $99 \%$ of the distribution ( $99 \%$ of negative occurrences) appears to be in the range of $15 \%$ for both Argentina and Mexico. The capital that would be required to cover $99.9 \%$ of the distribution is significantly higher at $21 \%$ for Argentina and $31 \%$ for Mexico.

We can compare these results with the level of capital that would be generated using the estimated probability of default and the formula proposed by the Basel Committee for the Foundation IRB approach. ${ }^{14}$ The Basel formula applied to the simulated PDs generates capital requirements equal to 9.7\% for Mexico, 14.1 for Brazil and $14.9 \%$ for Argentina (column 6), which appear considerably lower than those generated by our simulations at the $99.9 \%$ level of confidence.

\footnotetext{
${ }^{14}$ We have used the formula for assessing the capital requirement for the corporate portfolio as described in Basel Committee's Consultative Paper 3 (Basel Committee, 2003) and revised in the Basel Committee's note of January 2004 (Basel Committee, 2004).
} 
We can also compare our results with the capital requirements that would be generated by the Basel formula, using the corporate bond historical one year PD default rate computed by S\&P for different rating categories (column 8) and applying it to the similar rating obtained by each country for its sovereign risk in domestic currency exposures to obtain expected and unexpected losses (columns 9 and 10).

Finally we compare our results to those of a similar exercise conducted by Carey (2002) with a loan portfolio intended to mimic the risk exposure of a representative US banks. It is interesting to observe that the level of EL in a period of extreme stress such as that represented by the 1929 crisis would have been lower of the EL in a crisis scenario, as the Argentine one.

As an example of the many possible ad hoc applications of our resampling procedure, we report in the Appendix, a breakdown by banks of different size of the aggregate results reported in Table 3 and in Chart 2 for Mexico, that illustrates how risk exposures may vary across different groups of intermediaries.

Three preliminary conclusions can be drawn from the results. The first is that the Basel formula, applied to our sample of non-G10 countries, generates levels of protection inferior to the claimed $99.9 \%$. As the IRB is currently calibrated, the degree of protection would be in the range of $95-99 \%$ of the credit loss distribution. Another way to state this result is that to achieve the $99.9 \%$ level protection advocated by the Basel Committee, countries would require substantially increased capital requirements over and above the $8 \%$ minimum requirement advocated in Basel II. ${ }^{15}$ Moreover the fact that we have found

\footnotetext{
${ }^{15}$ Basel II's IRB formula in fact calculates assets at risk and then capital requirements are defined as $8 \%$ of assets at risk. So equally our results may be interpreted as saying that assets at risk must be larger
} 
a different overall level of required capital to achieve the level of protection theoretically granted by the Basel IRB curve, calls into question the curve calibration for individual instruments. In other words, given the types of default probabilities in emerging countries, it is not clear that the IRB curve, as written, would be appropriate to apply to individual instruments to ensure a good approximation to portfolio risk.

The second conclusion is that emerging countries may face a difficult choice if they wish to apply the IRB approach. They may either implement the IRB curve as it is written and hence implicitly opt for a lower degree of protection than that envisaged by the Basel Committee or they must attempt to recalibrate the curve and perhaps attempt to ensure a higher level of protection up to $99.9 \%$ as suggested by the BCBS. Of course this should not come as a surprise, as presumably the same type of issue arose with Basel I and indeed many countries adopted the Basel I methodology but with a higher minimum than the $8 \%$ figure recommended by the Basel Committee.

A third conclusion of our results is that, for emerging countries, the foundation IRB level of capital requirement is (notwithstanding its benevolent risk calibration), is likely to give higher capital requirements than the existing $8 \%$ minimum of the accord. In the case of Argentina, the IRB foundation approach gives a requirement of about $15 \%$ but in fact is close to actual capital requirements in Argentina at that time. ${ }^{16}$ In the case of Mexico and Brazil the foundation IRB approach would, according to our simulations,

(maintaining the $8 \%$ capital requirement) or that the $8 \%$ should be increased to achieve $99.9 \%$ protection. This discussion also assumes that provisions cover expected losses.

${ }^{16}$ Argentina had a baseline $11.5 \%$ capital requirement but various add-ons implied that the overall requirement was close to $15 \%$ of Basel calculated assets at risk. 
yield requirements of around 10\% and 14\% - higher than Basel's $8 \%$ and higher than current levels in Mexico (8\%) and in Brazil (11\%).

However, this discussion uses the IRB foundation approach with the actual default experience to measure the default probabilities. Using the S\&P corporate calibrated mappings from ratings to default probabilities and the rating of the relevant sovereign we obtain much lower figures. Such a rating is interpreted by rating agencies as the floor to non-government ratings and therefore the associated PD, EL and UL can be considered as a floor for corporate sector's PD, EL, and UL. Table 3 shows that, notwithstanding the lower level of capital requirements derived from S\&P ratings and probabilities of default, increased capital charges are likely to emerge for all Latin America and Caribbean countries starting from countries enjoying an investment grade rating such as Colombia, where the sum of EL and UL already exceeds the value of the all encompassing $8 \%$ capital requirement of the current Accord.

To conclude this section, our results suggest that, while the IRB foundation implies a rather generalized increase in capital requirements, it may not afford the $99.9 \%$ protection advocated by the BCBS given the default probabilities encountered in emerging countries. This result also calls into question the calibration of the published curve for use in these environments. Assuming provisions cover expected losses, our results indicate that to achieve $99 \%$ protection would require capital levels significantly higher than the Basel I's $8 \%$ and around a $15 \%$ overall requirement. To achieve $99.9 \%$ protection would require higher levels of capital. While these levels were close to Argentina's overall capital requirement in 2001, it would represent a steep increase in capital requirements for many countries. We now turn to consider how potentially 
different calibration results for emerging economies could fit into a Basel-compatible implementation strategy of risk based capital and loan loss reserves requirements.

\section{Policy Implications}

As stated, our estimations of required levels of capital are based on the assumption that provisions cover expected loss. In fact in some countries of the region, provisions may cover more than expected loss. In our simulations we defined default as more than 90 days past due and a loss given default of 50\%. And yet many countries ask for provisions of significantly higher than the level of expected losses for loans with past due payments inferior to 90 days, reaching $100 \%$ for loans above 90 days past due. This discussion underlines the need for a highly coordinated system for loan loss reserves and capital requirements. Indeed it is the sum of provisions and capital that should be compared against the value at risk (the sum of expected and unexpected loss) and not necessarily provisions against expected loss and capital against the unexpected component. Hence, if for some reason (legal or otherwise) there are impediments to increase capital to cover unexpected losses relative to the desired level of protection, then provisions might be increase over and above the level of expected loss.

The underlying need is then for a system to attempt to gauge the overall, value at risk of loans rather than their expected or unexpected loss components. This then calls into question the common system of (1) a general loan loss reserve (2) a specific loan loss classification and provision depending on past performance (say according to the traditional 5 category classification) and (3) a specified level of capital. 
The Basel II IRB framework suggests a minimum number of 9 loan classifications or buckets, leaving banks free to define the default probabilities assigned to each bucket. The IRB curve then defines the level of capital required given the default probability and other parameters. The IRB approach in fact simply validates some of what large, sophisticated G10 banks were already doing for their internal risk management purposes. The large banks have developed their own rating methodologies and have tested how their own ratings map into default probabilities and value at risk, both on an individual claim and on a portfolio basis. In fact many such banks are concerned that the approach does not give them sufficient freedom to use their own portfolio models of credit risk and must use the IRB formula to approximate the risk of a loan portfolio. ${ }^{17}$ Supervisors across G10 have been catching up in their understanding of the internal risk management models and have maintained this formula approach to ease with monitoring and because as yet they are concerned precisely with the parameter estimation risk and model risk discussed above.

With respect to developing countries the starting point may be very different. First, banks are in general less advanced in terms of developing internal rating methodologies, mapping those ratings into default probabilities and developing portfolio models. Indeed in some countries the motivation on the part of supervisors to move toward Basel II's IRB may be to get their banks to improve their own internal risk management, rather than catching up with what their banks are already doing. Second, supervisors have significantly less resources and in many countries supervisory skills and legal powers are sadly lacking. Indeed the statistics on compliance with the Basel Core Principals for

\footnotetext{
${ }^{17}$ See the comments by several large banks on the proposals on www.bis.org
} 
Effective Banking Supervision, conveys a quite worrying picture of poor and inadequate banking supervision across many developing countries. The average developing country is compliant with just seven of the 30 Basel Core Principals. ${ }^{18}$ This implies that it may be many years before supervisors in these countries would be advised to adopt the IRB approach that gives a high degree of autonomy for banks to determine their rating methodologies and how those ratings will feed into default probabilities.

We therefore suggest here a particular way to transit toward the IRB approaches using an integrated system for provisions and capital that may be easier for emerging country supervisors to monitor. We label this approach the centralized rating based approach. ${ }^{19}$

The idea is very similar to the IRB framework in that banks must rate their clients and each rating bucket translates into a default probability that is then mapped into a specific value at risk. However, the significant simplification with respect to the IRB approach is that the rating methodology and how the bank rating maps into a default probability is determined by the regulator. Thus the regulator stipulates the nine or more buckets and the default probability (mean, minimum and maximum) that corresponds to each bucket. Naturally this scale may for example conform to a scale used by a leading rating agency such as Standard and Poor's but bank supervisors may as well define a preferred scale that most suitably describes the risk exposure experience of their own

\footnotetext{
${ }^{18}$ In fact there are 25 BCPs, here we could the sub-Principles of principle 1 as Principles in their own right to obtain 30 .

${ }^{19}$ See also Powell (2001) and Powell (2004).
} 
country. ${ }^{20}$ Banks must then simply slot their clients into the buckets suggested by the regulator but based on their estimation of each borrower's probability of default.

How would capital requirements be defined? To some extent this would depend on the particular constraints, legal or otherwise on the regulator. One approach, for regulators with few constraints, would be to rely on observed PDs and use the Basel II curve to calculate unexpected losses and set provisions and capital to cover expected and unexpected losses respectively. A second approach could be considered, however, if provisions could not be altered for whatever reason. In this case capital could be set to equal Value at Risk minus the allowable provisions along the lines suggested by the Base Committee in the revisions of the Consultative Paper 3 aimed at insuring a better integration of bank capital requirements and loan loss reserves (Basel Committee, 2004). A third approach, for regulators that have freedom to alter provisions but prefer a simple rule for capital, would be to adopt the Basel II standardized approach but then have forward looking provisions determined by the value at risk minus the Basel II SA approach capital requirement. This last approach would then use the CRB approach to enhance forward-looking provisions rules and in a fashion totally consistent with Basel II. Moreover, over time banks internal rating methodologies would be developed and allow such banks, once ready, to move over to the full IRB approach.

This approach suffers from one disadvantage. Namely each bank would be forced to use the same rating scale (but not necessarily the same rating for each client as banks' opinions might differ). This means that a bank specializing in one type of business or

\footnotetext{
${ }^{20}$ See, for a supervisory based application based on cluster analysis the paper by Foglia et al. (2001).
} 
region would have to use the same rating scale as a bank in another line of business or region. Put another way, as the buckets would be essentially defined by the minimum and maximum default probabilities, the default probability range of each bucket may not be the ideal one for each bank. Some banks may have a large number of clients in one or two buckets of the centralized whereas if they used an internal scale then they could open those buckets into finer ones with a smaller range of default probabilities. However, the supervisor would devise the buckets to be appropriate for the larger, more important institutions in the banking sector. ${ }^{21}$ Then, by definition, the problems indicated, which would essentially be problems of how the requirements approximated to the relevant risks, would only be for smaller and non-systemic institutions.

On the other hand, we suggest that there are many advantages of the CRB approach as a transition tool to the IRB approaches:

- Lower monitoring costs for bank supervisors. Supervisors would have to verify the quality of banks' methodologies to slot clients into the relevant buckets. Supervisors could very easily compare on this homogenous scale different banks' ratings of particular corporates, corporates of similar characteristics, corporates in particular economic sectors or regions etc. Moreover the homogenous scale would

\footnotetext{
${ }^{21}$ In a more complex proposal the regulator could allow the use of more than one centralized scale reflecting different banking specializations. Interestingly the Hong Kong Monetary Authorities (HKMA) planned the introduction of a loan classification regulation similar to that described in this paper (HKMA, 2002) with loan grades characterized by an upper and lower probability of default for each grade. The large number of Hong Kong banks that eventually opted for IRB approach did not make the implementation of the regulation necessary, but the scheme preserve its full validity for countries where the majority of banks will not opt for an IRB approach or where supervisory resources may be inadequate to face the challenges of the IRB approach.
} 
allow the supervisor to easily aggregate ratings and default experience to back-test the mapping from the rating buckets to the default probabilities.

- The system would ensure a consistent treatment of capital and loan loss reserves. This is of course a vital component of Pillar 2 and Basel Core Principle 8.

- Favor the development of a risk based capacity within the banking system independently from each country decision to officially remain in Basel I or to adopt the different options of Basel II.

- The homogeneity of bank classification schemes would provide the system of an important additional property: individual banks data could be aggregated at a country level generating an important, so far mostly missing, information about the cyclical developments of credit quality. It would also make possible to monitor the effect of structural reforms (legal, regulatory, dissemination of credit information) on the quality of credit and on the cost of credit. Current Basel II arrangements under the IRB preclude such developments and have not considered the important public good element represented by this information externality).

\section{Conclusions}

In this paper we have discussed a simple methodology for the integrated estimation of expected and unexpected losses for countries that have a source of centralized credit information, such as a credit register, and we have shown how these estimates can provide the basis for a simplified risk based bank solvency regulation that is compatible with Basel II and could be used by countries that are not yet ready to adopt the IRB approach. 
We have employed a homogeneous bootstrapping methodology to analyze credit risk in three emerging markets in Latin America. We believe that this is the first attempt to provide estimations of credit risk in banks across different emerging countries using a homogeneous methodology. While our results are limited as they correspond to a photograph at one time period, rather than measuring risk across the whole economic cycle, the time period chosen was one of stress in each of the three economies, albeit before the worst of the Argentine crisis. The bootstrapping methodology implies that our estimates are free from the usual problems of parameter estimation error and model error that plague standard attempts to measure portfolio credit risk.

The results indicate that in order to achieve a $99 \%$ level of protection (in other words such that capital covers the unexpected loss to $99 \%$ of the distribution), capital requirements would need to be significantly higher than Basel I's $8 \%$ and closer to $15 \%$ close to Argentina's overall requirement at that time. In order to achieve $99.9 \%$ protection, as per the advertised goal in Basel II, would require significantly higher numbers. These results assume that provisions cover expected losses. However, given that several countries require provisions to exceed expected losses, the amount of capital needed to cover a $99.9 \%$ level of value at risk may be significantly lower than that suggested by the level of unexpected losses. We also find that Basel II's foundation IRB approach, while resulting in increases in capital requirements above Basel I, would result in levels closer to the $90-95 \%$ protection rather than the $99.9 \%$ level stated as used in its calibration. This calls into question the calibration of the IRB curve for use in emerging countries. We believe that further research is required in this area to consider if and how 
the Basel II IRB might be recalibrated for countries that wish to adopt this approach but that have default probabilities significantly higher than the G10's.

In the second part of the paper, we discussed issues regarding the implementation of Basel II's IRB approach in emerging countries. In particular we suggested that many emerging countries may be many years away from IRB implementation. Clearly a first priority for many countries is to improve supervisory skills and enhance resources and work on legal issues to more fully comply with the Basel Core Principals for Effective Banking Supervision. Given that this process will take time, we suggest a simpler Centralized Rating Based approach as a way to transit toward the IRB.

The main difference with the IRB approach is that although banks would rate their clients, the regulator would set the rating methodology by defining the way in which the rating buckets would map to default probabilities. We suggest that initially this approach could be used to set forward-looking provisioning requirements. A country could then adopt Basel II's standardized approach, set provisions using the CRB methodology to cover the value at risk minus the Basel II's SA capital and in that way ensure that banks' total reserves (provisions plus capital) covered the entire value at risk up to the desired level of protection. 


\section{References}

Altman, E. I and A. Saunders., (1998). "Credit risk measurement: Developments over the last 20 years", Journal of Banking and Finance.

Balzarotti, V., M. Falkenheim and A. Powell (2001) "On the use of portfolio risk models and capital requirements in emerging markets : the case of Argentina", World Bank Economic Review 2002 16: 197-212.

Balzarotti, V., C. Castro and A. Powell "Reforming Capital Requirements in Emerging Countries: Calibrating Basel II using Historical Argentine Credit Bureau Data and CreditRisk+" mimeo. Universidad Torcuato Di Tella prepared for World BankASBA-Bacen conference, Rio de Janeiro February $13^{\text {th }} 2004$.

Cavallo, M. and G. Majnoni, "Do Bank Provision for Bad Loans in Good Times? Empirical Evidence and Policy Implications", in "Ratings, Rating Agencies and the Global Financial System" eds. Richard Levich, Giovanni Majnoni, and Carmen Reinhart, Kluwer Academics Publishers, 2002.

Basel Committee on Bank Supervision, (2003) "Consultative Document: Overview of New Capital Accord", April.

-- $\quad$, (2004)"Modification to the Capital Treatment for Expected and Unexpected Credit Losses in the New Basel Accord", January.

Carey, M (1998), “Credit risk in private debt portfolios”, Journal of Finance, Vol. 53: pp.1363-87, August

-- $\quad$, (2002). "A guide to choosing absolute bank capital requirements", Journal of Banking and Finance, n.1.

Cronemberg, G., S. Mikio, V. Salomao, R. Schechtman, (2003), “Credit Information, Credit Risk Measurement, and the Regulation of Bank Capital and Provisions in Mexico", Banco Central do Brazil, mimeo.

Falkenheim M. and A. Powell, (2000). "The use of credit bureau information for the estimation of credit risk: the case of Argentina", mimeo, Central Bank of Argentina.

Ferri, G., Li-Gang L., and G. Majnoni (2001), "The Role of Rating Agencies Assessments in Less Developed Countries: Impact of the Proposed Basel Guidelines", Journal of Banking and Finance, Vol. 25, No. 1.

Foglia, A., (2003), "Using Credit register and Company Account Data for Measuring Credit Risk: A Supervisory Approach”, Banca d'Italia, mimeo.

Foglia, A., S. Iannotti, P Marullo Reedtz, (2001), "The Definition of the Grading Scales in Bank's Internal Rating Systems”, Banca d'Italia, mimeo.

Hong Kong Monetary Authority, (2002), "Revision of Loan Classification System”, mimeo, September.

Kupiec, P. (2001). "Is the new Basel Accord incentive compatible", mimeo, IMF.

Laeven, L. and G. Majnoni, "Loan Loss Provisioning and Economic Slowdowns: Too Much, Too Late?", Journal of Financial Intermediation, Vol 12, pp.178-197, 2003. 
Majnoni, G., M. Miller, N. Mylenko, and A Powell, (2004) "Improving Credit Information, Bank Regulation, and Supervision: On the Role and Design of Public Credit Registries “, mimeo.

Marquez, J., J. L. Negrin, P. O’Dogherty, A.Werner, (2003), “Credit Information, Credit Risk Measurement, and the Regulation of Bank Capital and Provisions in Mexico", Banco de Mexico, mimeo.

Miller, M., (2003). Credit Reporting Systems and the International Economy, MIT Press, Cambridge.

Pagano, M., ed., Defusing Default: Incentives and Institutions, Washington, Johns Hopkins University Press.

Powell, A., (2002). “A capital accord for emerging economies?” World Bank, Policy Research Working Paper, n. 2808.

-- , (2004) "Basel II and Developing Countries: Sailing through the Sea of Standards" mimeo. World Bank and Universidad Torcuato Di Tella. 
Figure 1. Argentina: Relevant Frequency Distributions from the Resampling Exercise
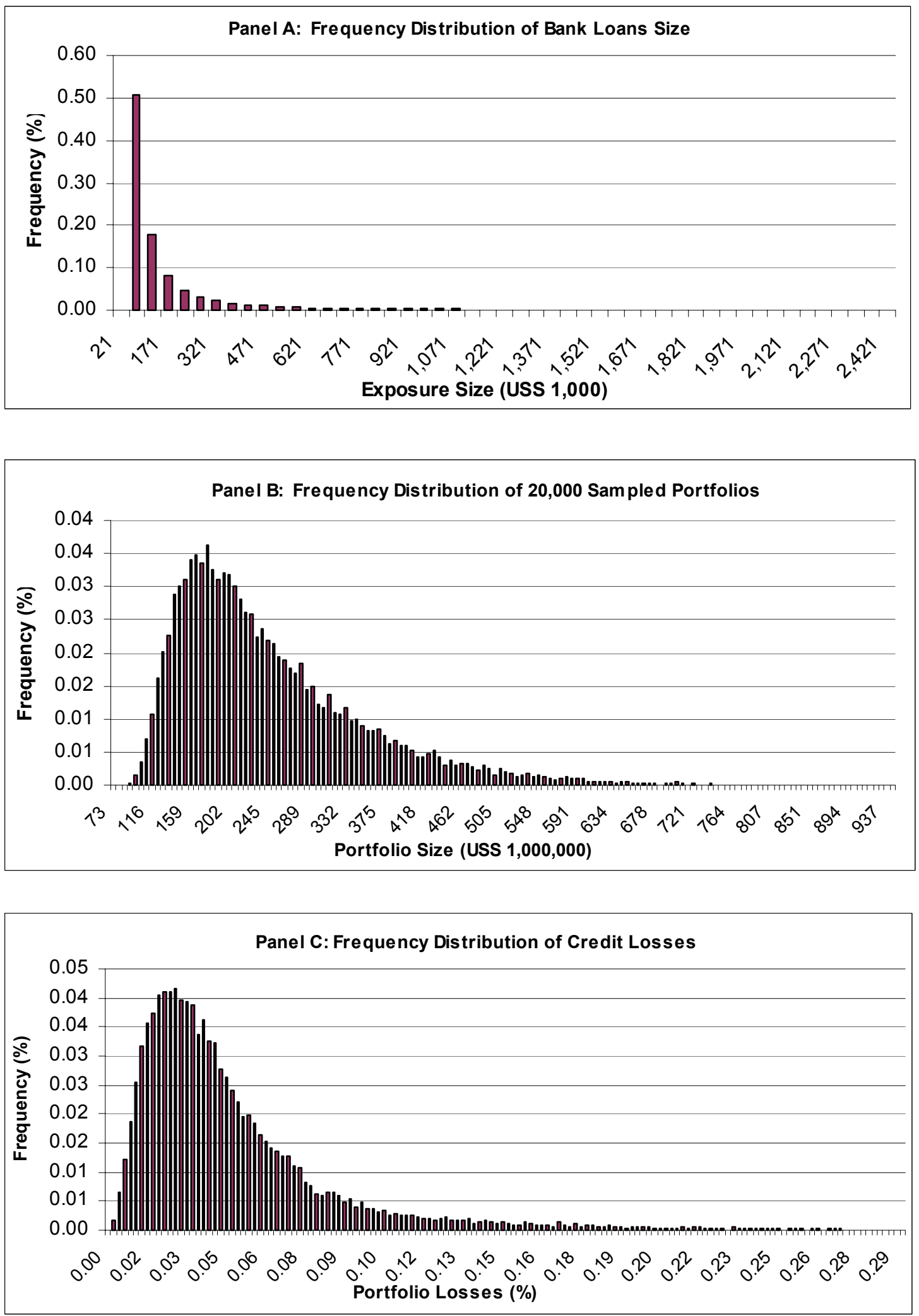
Figure 2. Mexico: Relevant Frequency Distributions from the Resampling Exercise
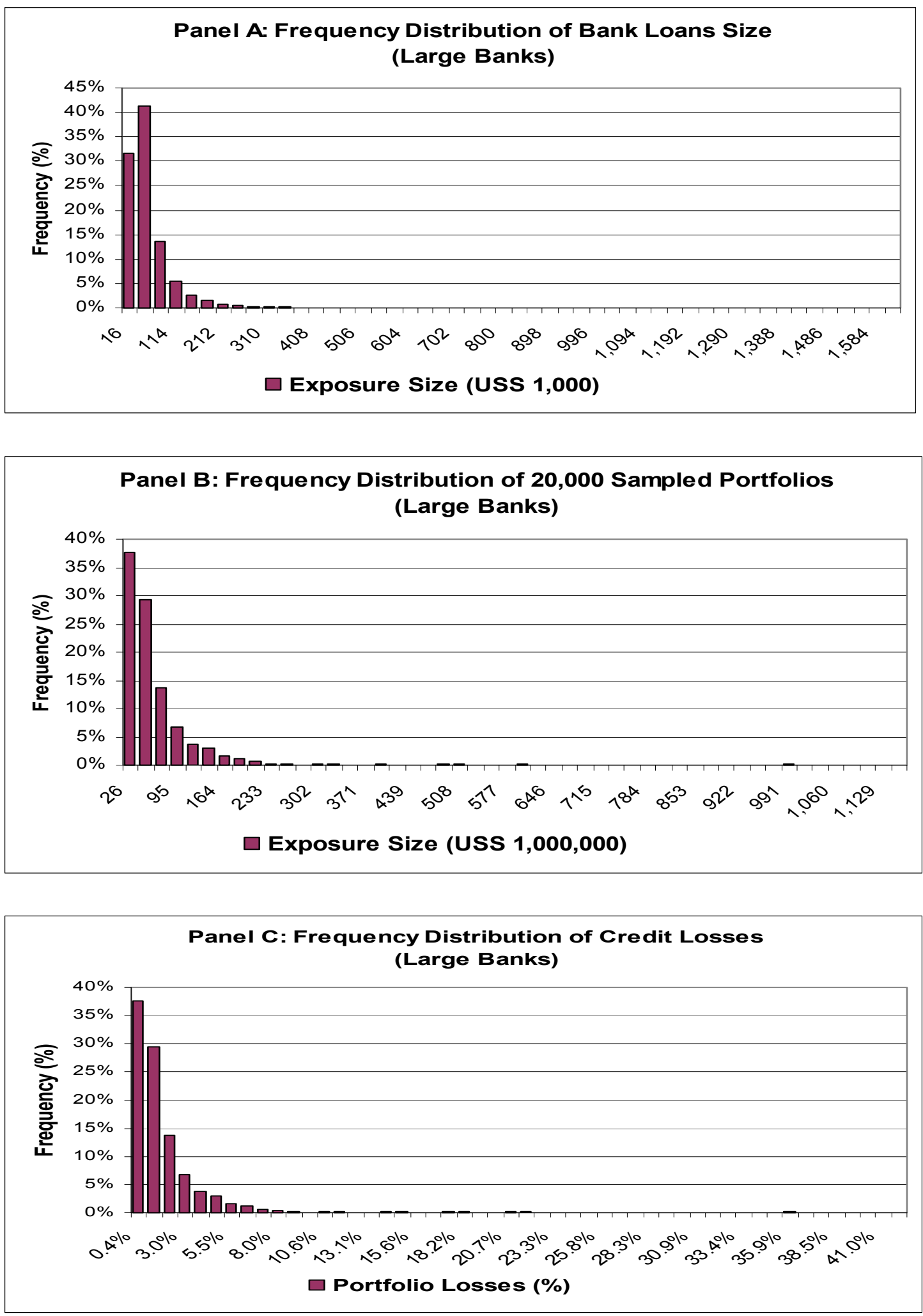
Figure 3. Brazil: Relevant Frequency Distributions from the Resampling Exercise
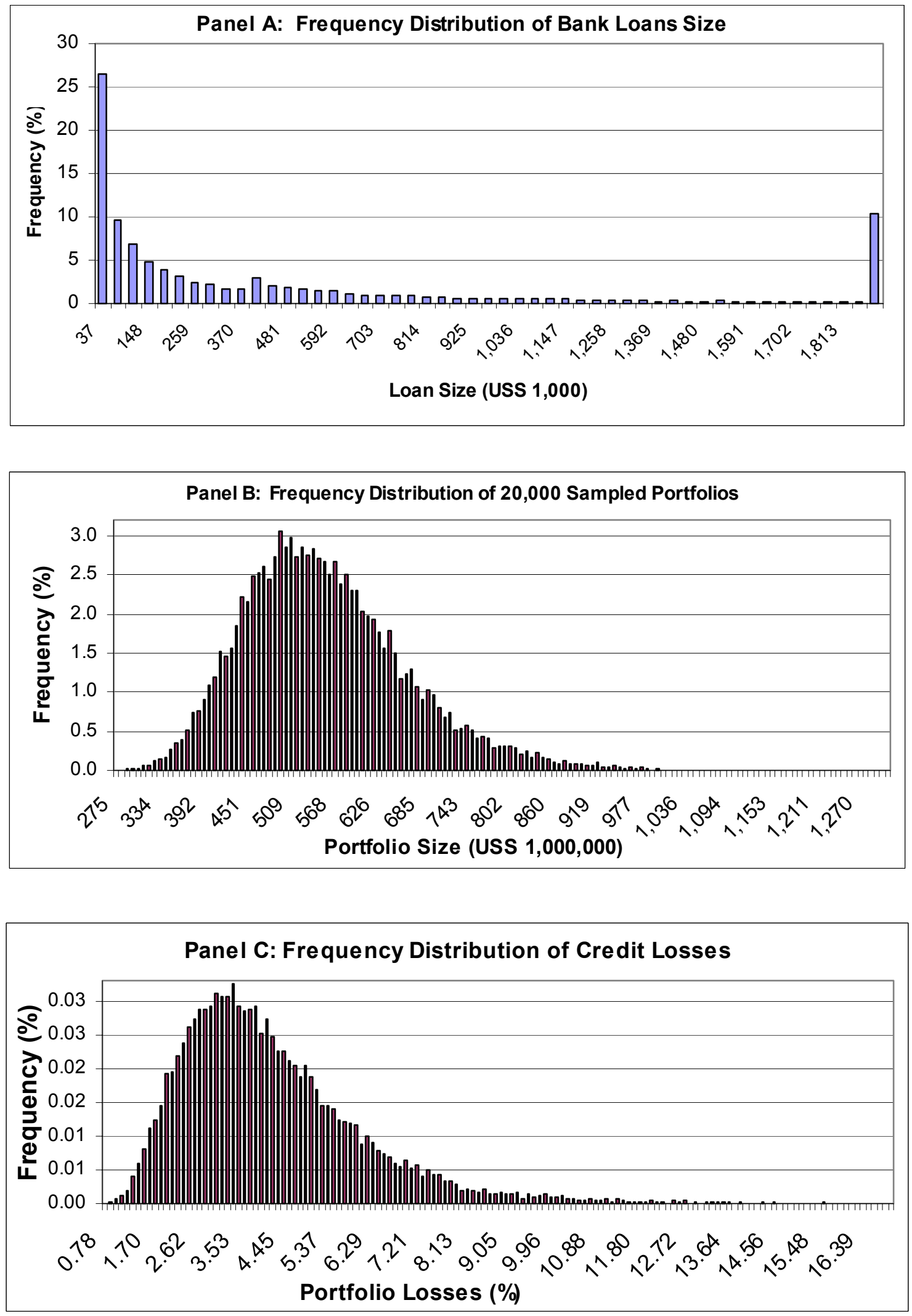


\section{Table 1: Simulated Loan Portfolios: Descriptive Statistics}

Data refer to the 12 months period indicated for each country. The Number of Observations refer to the number of bank loans to non financial entities and above a certain minimum size that were extracted from the national credit registers of each country at the beginning of the 12 months period. The criteria underlying the selection of loans from the credit registers differ slightly across countries. For Mexico and Argentina, a loan refers to the overall position of a single borrower with the banking system as a whole. The positions selected are those larger or equal to US $\$ 21,000$ for Argentina. For Mexico in addition to loans larger or equal than US\$20,000, reported on a compulsory basis, are included loans of smaller size that are reported on a voluntary basis. For Brazil the minimum size is higher and equal to US\$300,000 but positions with different banks that concur to define the total exposure are treated as distinct individual loans. The descriptive statistics (Mean, Median, Mode, Stand Dev. Min and Max) refer to the distribution of the value of the 20,000 portfolio of 500 loans each, randomly sampled from the pool of loans described above. Exact sources and definitions of each variable can be found in the main text.

\begin{tabular}{|c|c|c|c|c|c|c|c|c|}
\hline & Country & N. Obs. & $\begin{array}{l}\text { Mean } \\
\text { (\$ mln) }\end{array}$ & $\begin{array}{l}\text { Median } \\
\text { (\$ mln) }\end{array}$ & $\begin{array}{l}\text { Mode } \\
\text { (\$ mln) }\end{array}$ & $\begin{array}{l}\text { St. Dev. } \\
\text { (\$ mln) }\end{array}$ & $\begin{array}{c}\text { Min } \\
\text { (\$ mln) }\end{array}$ & $\begin{array}{c}\text { Max } \\
\text { (\$ mln) }\end{array}$ \\
\hline Mexico & (Dec.2000-Dec.2001) & 188,165 & 85 & 62 & 33 & 89 & 16 & 1,477 \\
\hline Argentina & (Dec.2000-Dec.2001) & 70,017 & 242 & 215 & 182 & 104 & 72 & 943 \\
\hline Brazil & (Oct.2001-Oct.2002) & 41,784 & 551 & 538 & 510 & 110 & 275 & 1,306 \\
\hline
\end{tabular}




\section{Table 2: Capital and Provisions: Unexpected and Expected Losses Estimations Based on Simulation Results and on S\&P Observed Average Default Frequency}

Expected Loss (EL) in the simulation results section is given by the mean value of the simulated distribution of credit losses. Simulations are based on the random extraction without replacement of 500 loans from the pool of loans registered in the Credit Register of each country, to simulate a standard bank loan portfolio. The extraction is repeated 20,000 times (this time with replacement) to obtain 20,000 portfolios. The distribution of credit losses for each portfolio provides the 20,000 observations used to simulate the distribution of credit losses. Unexpected Losses (UL) at different levels of probability represent the value of credit losses (as a percentage of the face value of the portfolio) corresponding the percentile on the right tail of the distribution minus the EL given by the mean value of the distribution. Basel UL indicates the value of Unexpected Losses (UL) computed according to the algorithm proposed by the Basel Committee in its January 30, 2004 document. The value of PD used in the algorithm is given by half the value of the EL, assuming the same $50 \%$ Loss Given Default (LGD) used in the simulation exercise. In the section of the table related to S\&P based statistics, RATING represents the lowest value of domestic currency sovereign rating expressed by S\&P over the time period considered. This is only partially true in the case of Argentina, where we have conventionally selected a rating of CCC, although the formal rating was suspended in November 2001 on the eve of the Government's default on its sovereign debt. PD is computed on the basis of the historical average one year default frequency on S\&P rated corporate bonds; LGD has been assumed equal to $50 \%$. Basel UL refers to the value of Unexpected Losses (UL), computed according to the algorithm proposed by the Basel Committee in its January 30, 2004 document and using the value of PD corresponding to the EL/LGD value. Per Memoriam are reported the results of the simulation of credit losses presented in Carey (2002) and based on the use of a loan portfolio that mimics the risk exposure of a medium size bank in the USA and applying the PD values observed at times of systemic distress such as during the 1989-91 moderate recession in the USA and during the 1929 recession.

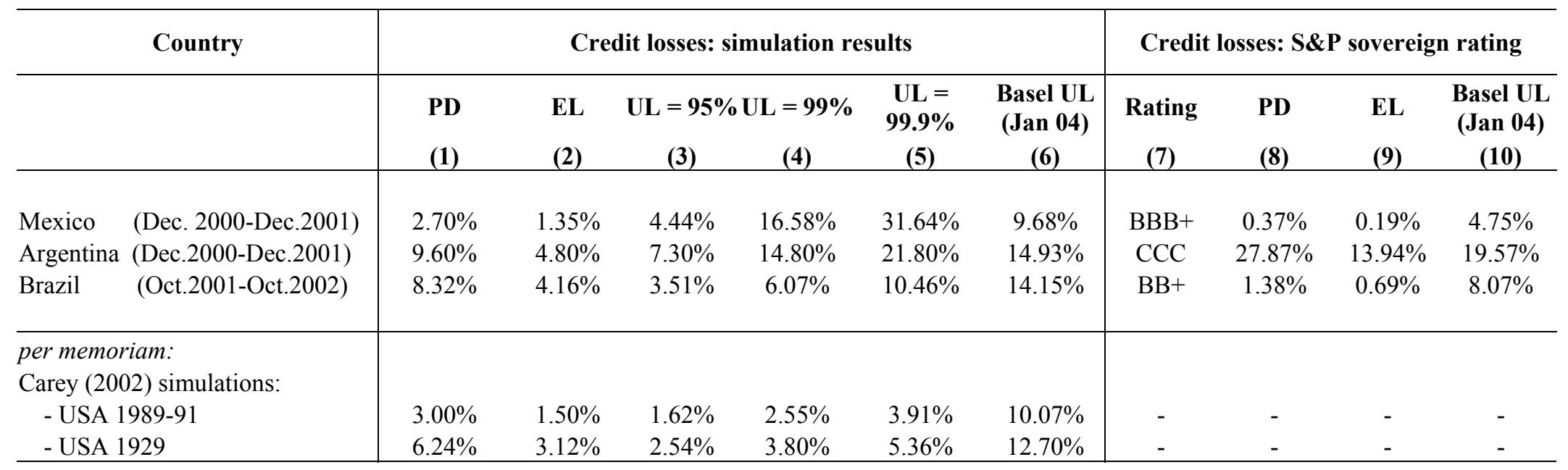




\section{Table 3: Capital and Provisions in Latin American Countries Based on S\&P Ratings}

Country classification refers to Standard and Poors' domestic currency sovereign rating as of December 2003. The variable expected loss (EL) is the product of the probability of default (PD) and of the loss given default (LGD). PD is computed on the basis of the historical average one year default frequency on S\&P rated corporate bonds; LGD has been assumed equal to $50 \%$. Basel UL refers to the value of Unexpected Losses (UL) computed according to the algorithm proposed by the Basel Committee in its January 30, 2004 document and using the value of PD corresponding to the EL/LGD value.

\begin{tabular}{|c|c|c|c|c|}
\hline $\begin{array}{c}\text { S\&P } \\
\text { classification }\end{array}$ & Countries & EL & $\begin{array}{l}\text { Basel UL } \\
\text { (Jan 04) }\end{array}$ & $\mathbf{E L}+\mathbf{U L}$ \\
\hline AAA & - & $0.00 \%$ & $0.34 \%$ & $0.34 \%$ \\
\hline $\mathrm{AA}$ & Chile & $0.00 \%$ & $0.61 \%$ & $0.62 \%$ \\
\hline A & Barbados, México, Trinidad \&Tobago & $0.02 \%$ & $1.56 \%$ & $1.59 \%$ \\
\hline BBB & Colombia & $0.17 \%$ & $4.75 \%$ & $4.91 \%$ \\
\hline $\mathrm{BB}$ & $\begin{array}{l}\text { Belize, Brazil, Costa Rica, El Salvador, } \\
\text { Guatemala Panama, Peru, }\end{array}$ & $0.62 \%$ & $8.07 \%$ & $8.69 \%$ \\
\hline B & $\begin{array}{l}\text { Bolivia, Jamaica, Suriname, Uruguay, } \\
\text { Venezuela }\end{array}$ & $2.71 \%$ & $12.54 \%$ & $15.25 \%$ \\
\hline $\mathrm{CCC}$ & Ecuador, Paraguay, Dominican Rep & $12.54 \%$ & $19.57 \%$ & $32.11 \%$ \\
\hline
\end{tabular}




\section{APPENDIX: Mexico: Simulated Expected and Unexpected Credit Losses for Banks of Different Size}

\section{Table A1: Simulated Loan Portfolios: Descriptive Statistics}

Data refer to loans registered in the Mexican Credit Register. The Number of Observations refer to the number of bank loans to non financial entities at the end of in December 2000. A loan refers to the overall position of a single borrower with the banking system as a whole. In addition to loans larger or equal than US $\$ 20,000$, reported on a compulsory basis, are included loans of smaller size that are reported on a voluntary basis. The descriptive statistics (Mean, Median, Mode, Stand Dev. Min and Max) refer to the distribution of the value of the 20,000 portfolio of 500 loans each, randomly sampled from the pool of loans described above. Exact sources and definitions of each variable can be found in the main text.

\begin{tabular}{|c|c|c|c|c|c|c|c|}
\hline Bank size & N. Obs. & $\begin{array}{c}\text { Mean } \\
\text { (\$ mln) }\end{array}$ & $\begin{array}{l}\text { Median } \\
\text { (\$ mln) }\end{array}$ & $\begin{array}{c}\text { Mode } \\
\text { (\$ mln) }\end{array}$ & $\begin{array}{l}\text { St. Dev. } \\
\text { (\$ mln) }\end{array}$ & $\begin{array}{c}\text { Min } \\
(\$ \mathbf{~ m l n})\end{array}$ & $\begin{array}{c}\text { Max } \\
\text { (\$ mln) }\end{array}$ \\
\hline Small & 2,984 & 344 & 340 & 306 & 52 & 200 & 623 \\
\hline Médium & 47,532 & 115 & 91 & 87 & 84 & 27 & 929 \\
\hline Large & 137,649 & 67 & 45 & 67 & 85 & 14 & 1,163 \\
\hline Total Banking System & 188,165 & 85 & 62 & 33 & 89 & 16 & 1,477 \\
\hline
\end{tabular}

Table A2: Capital and Provisions: Unexpected and Expected Losses
Estimations Based on Simulation Results

Expected Loss (EL) in the simulation results section is given by the mean value of the simulated distribution of credit losses. Simulations are based on the random extraction without replacement of 500 loans from the pool of loans registered in the Credit Register of each country, to simulate a standard bank loan portfolio. The extraction is repeated 20,000 times (this time with replacement) to obtain 20,000 portfolios. The distribution of credit losses for each portfolio provides the 20,000 observations used to simulate the distribution of credit losses. Unexpected Losses (UL) at different levels of probability represent the value of credit losses (as a percentage of the face value of the portfolio) corresponding the percentile on the right tail of the distribution minus the EL given by the mean value of the distribution. Basel UL indicates the value of Unexpected Losses (UL) computed according to the algorithm proposed by the Basel Committee in its January 30, 2004 document. The value of PD used in the algorithm is given by half the value of the EL, assuming the same 50\% Loss Given Default (LGD) used in the simulation exercise.

\begin{tabular}{l|rrrrr}
\hline \multicolumn{1}{c|}{ Bank size } & \multicolumn{5}{|c}{ Credit losses: simulation results } \\
& PD & $\mathbf{E L}$ & $\mathbf{U L}=\mathbf{9 5 \%}$ & $\mathbf{U L}=\mathbf{9 9 \%}$ & $\mathbf{U L}=\mathbf{9 9 . 9 \%}$ \\
& $\mathbf{( 1 )}$ & $\mathbf{( 2 )}$ & $\mathbf{( 3 )}$ & $\mathbf{( 4 )}$ & $\mathbf{( 5 )}$ \\
\hline & & & & & \\
Medium & $4.16 \%$ & $2.08 \%$ & $5.91 \%$ & $12.69 \%$ & $22.16 \%$ \\
Large & $1,96 \%$ & $0.98 \%$ & $3.01 \%$ & $18.39 \%$ & $35.79 \%$ \\
Total Banking System & $2.70 \%$ & $1.35 \%$ & $4.44 \%$ & $16.58 \%$ & $31.64 \%$ \\
& & & & & \\
\hline
\end{tabular}

